\title{
PERCEPTIONS OF NEIGHBORHOOD CHARACTERISTICS AND THE PERCEIVED PSYCHOSOCIAL AND ACADEMIC OUTCOMES OF U.S. CHILDREN AND ADOLESCENTS
}

\author{
Godwin S. Ashiabi
}

\begin{abstract}
Data from the 2007 National Survey of Children's Health were used to examine a model of the ways in which neighborhood structural characteristics and social processes (NSCSP) impact children's (age $=6-11 ; N=27,752$ ) and adolescents' (age $=12-17 ; N=36,233$ ) social adjustment and school engagement via parenting and family processes (i.e., parent-child interactions). The questions investigated were: how are distinct aspects of NSCSP associated with parental stress and well-being, and with youth social adjustment and school engagement? Are parental stress and well-being linked with family processes, and are family processes predictive of youth social adjustment and school engagement? Finally, does age moderate the associations linking NSCSP to developmental outcomes via parenting stress and well-being and family processes? Results from a multigroup structural equation model supported the general nature of hypothesized relationships: distinct aspects of NSCSP were differentially predictive of children and adolescents' social adjustment and school engagement. Furthermore, the direct effects of NSCSP were mediated (some partially and others completely) by parenting stress and well-being and family processes. Finally, age moderated the effects of social cohesion on both social adjustment and school engagement; as well, age moderated the effects of parenting stress and well-being on family processes, and on the effects of family processes on social adjustment and school engagement.
\end{abstract}

Keywords: family processes; parenting stress and well-being; school engagement; social adjustment; neighborhood structural characteristics and social processes.

Godwin S. Ashiabi PhD is an Associate Professor of Psychology at the Gulf University for Science and Technology, Department of Humanities and Social Sciences, W1-211, Block 5, Building 1, P.O. Box 7207, Hawally 32093, Kuwait. Email: ashiabi.g@ gust.edu.kw 
International Journal of Child, Youth and Family Studies (2017) 8(3-4): 168-189

A large volume of empirical and theoretical work has associated neighborhood structural characteristics and social processes (NSCSP) to community levels of delinquency (Bursik \& Grasmick, 1996; Sampson \& Groves, 1989; Sampson, Morenoff, \& Earls, 1999; Sampson, Raudenbush, \& Earls, 1997; Wilson, 1996) and children and adolescents' development (Caughy et al., 2012; Kohen, Leventhal, Dahinten, \& McIntosh, 2008; McNulty \& Bellair, 2003; Tolan, Gorman-Smith, \& Henry, 2003). Since the classic work of Shaw and McKay (1942) linked neighborhood social disorganization and social control to crime rates, researchers have continued to investigate the association between neighborhood characteristics and social processes and youth development.

Contemporary research within the sociological tradition (Bursik \& Grasmick, 1996; Sampson \& Groves, 1989; Stark, 1987; Wilson, 1996) has reinterpreted and extended social disorganization theory by including the notion of neighborhood social processes, thereby increasing our understanding of the connections between neighborhood characteristics and social processes and delinquency (Kubrin \& Weitzer, 2003). The systemic view of social disorganization (Bursik \& Grasmick, 1996) has suggested that different forms of weakened social control serve as a mediator between neighborhood disorganization and youth development. Cantillon, Davidson and Schweitzer (2003), using a systemic model of social disorganization, reported that a sense of community (a feeling of belongingness, that one matters, and shared faith of one's needs being met) mediated the effects of neighborhood disadvantage on adolescent outcomes.

Within the social capital and collective efficacy model of social disorganization (Sampson \& Groves, 1989; Sampson et al., 1997, 1999), Sampson and Groves (1989) tested a mediational model of the social control aspect of social disorganization theory. Utilizing data from Great Britain, they linked structural aspects of neighborhoods (poverty and residential mobility) to social control (friendship networks and teenage peer groups) and found an association with criminal victimization. They argued that neighborhood social disorganization reduces social capital and collective efficacy; these, in turn, increase the rates of criminal victimization. Sun, Triplett, and Gainey (2004) examined and extended Sampson and Groves' (1989) hypothesis that neighborhood structural disadvantages and low social control will be predictive of increased crime rates. Using data from seven U.S. cities, Sun et al. reported that social disorganization mediated the effects of neighborhood structural characteristics more effectively on assault than it did on robbery.

Other investigators using the social disorganization framework have explored the relations among neighborhoods, family life, and youth development (McNulty \& Bellair, 2003; Tolan et al., 2003). McNulty and Bellair (2003) reported that the effect of concentrated disadvantage on violence was mediated by family well-being. Tolan et al. (2003) in their developmental-ecological model reported that parenting practices partially mediated the 
relationship between NSCSP and gang membership. Chung and Steinberg (2006), in a study of how NSCSP, parenting, and peers influence adolescents' development, reported that weak neighborhood social organization was related to delinquency through its associations with parenting behavior and peer deviance.

Researchers with an individual developmental orientation have also sought to understand parental, family and child level factors that mediate or moderate the association between NSCSP and individual development (Anthony \& Nicotera, 2008; Booth, Ayers, \& Marsiglia, 2012; Caughy et al., 2012; Dorsey \& Forehand, 2003; Gonzales et al., 2011; Kohen et al., 2008; Vieno, Nation, Perkins, Pastore, \& Santinello, 2010). Developmental research on neighborhood effects on child and youth development have found a mediational path via parental psychological distress, family processes, and parent-child relationship constructs (Kohen et al., 2008; Kotchick, Dorsey, \& Heller, 2005; Law \& Barber, 2007; White, Roosa, Weaver, \& Nair, 2009). Kohen et al. (2008) reported that lower neighborhood cohesion was associated with maternal distress and family dysfunction, which, in turn, were correlated to poor quality parenting behaviors, and ultimately, poorer child outcomes. Kotchick et al. (2005), using family stress theory, examined a longitudinal model of the associations among neighborhood stress, maternal psychological functioning, and parenting (with social support as a moderator) among African American single mothers. They reported that higher levels of neighborhood stress were related to greater psychological maternal distress; maternal distress was then related to less positive parenting practices. A moderating effect also emerged for social support. White et al. (2009) also tested the family stress theory to examine the associations between neighborhood, economic, and acculturative stressors and parenting behaviors. Their findings supported the hypothesis that the negative impact of economic stress on parenting was via parental depressive symptoms.

Other developmental studies have focused on the (perceived) safety or dangerousness of neighborhoods (Booth et al., 2012; Ceballo \& McLoyd, 2002; Dorsey \& Forehand, 2003). Violence or the threat of violence has been implicated in the cognitive, emotional, and behavioral outcomes of children (Richters \& Martinez, 1993; Schechter \& Willheim, 2009). Exposure to violence is related to internalizing disorders (Cooley-Quille, Boyd, Frantz, \& Walsh, 2001; Fitzpatrick, Piko, Wright, \& LaGory, 2005) and to physical and mental health problems (Berenson, Wiemann, \& McCombs, 2001; Salzinger, Feldman, Stockhammer, \& Hood, 2002).

Booth et al. (2012) reported that the influence of neighborhood safety on adolescents' psychological distress was partly mediated by their feelings of powerlessness, social isolation, and mistrust. Dorsey and Forehand (2003) in a study of how social capital, neighborhood dangerousness, and positive parenting relate to children's externalizing and internalizing behaviors reported that social capital was associated with child adjustment difficulties through positive parenting and neighborhood dangerousness. In an Italian study that explored the associations between neighborhood social capital, safety concerns, parenting, and adolescent antisocial behavior, Vieno et al. (2010) reported that social capital was inversely related to safety concerns and positively to parental support and solicitation. In turn, safety concerns were 
International Journal of Child, Youth and Family Studies (2017) 8(3-4): 168-189

positively related to parental support and solicitation. Social capital and safety concerns had indirect effects on children's antisocial behavior through their effects on parenting.

Both within the social organization and developmental literatures, little attention has been paid to the developmental significance of the built physical environment (Gorman-Smith \& Schoeny, 2009). However, environmental psychological research (Nasar \& Fisher, 1993; Nasar, Fisher \& Grannis, 1993) and theoretical reviews (Evans, 2006; Ferguson, Cassells, MacAllister, \& Evans , 2013) have demonstrated the developmental significance of the deterioration of the built physical environment. Investigations suggest that deteriorated physical environments contribute to fear among residents (Nasar \& Fisher, 1993; Taylor, Shumaker, \& Gottfredson, 1985). The persistent experience of fear has been linked to cognitive and academic (Shonkoff, Boyce, \& McEwen, 2009) and social and emotional difficulties (Arnsten, 2009).

Those working within the social disorganization framework have generally focused on the effects of NSCSP at the community level, not on individual development (Gorman-Smith \& Schoeny, 2009). Additionally, a majority of these studies have focused only on youth in urban, disadvantaged neighborhoods (Gorman-Smith \& Schoeny, 2009), with a predominant emphasis on atypical outcomes rather normative outcomes (Caughy et al., 2012). As well, most studies have not explored the multiple dimensions of neighborhoods, nor addressed the processes that link these dimensions to specific developmental outcomes (Cuellar, Jones, \& Sterrett, 2015; Leventhal \& Brooks-Gunn, 2000). Furthermore, a majority of studies have used aggregate census data to link neighborhoods to particular outcomes (Hadley-Ives, Stiffman, Elze, Johnson, \& Dore, 2000; Leventhal \& Brooks-Gunn, 2000); however, the aggregate approach has limited utility in helping to unravel specific neighborhood effects on development (Booth et al., 2012; Hadley-Ives et al., 2000).

\section{The Present Study}

The current study draws on social disorganization (Sampson \& Groves, 1989; Sampson et al., 1977, 1999; Wilson, 1996) and family stress theories (Conger \& Elder, 1994; McLoyd, 1990), environmental psychology (Evans, 2006; Nasar \& Fisher, 1993; Nasar et al., 1993), and theoretical formulations (Cuellar et al., 2015; Leventhal \& Brooks-Gunn, 2000) to examine the processes via which neighborhood structural and physical characteristics and social processes influence developmental outcomes. The present study advances prior research in several ways: it employs a developmental framework (6- to 11-year-olds vs. 12- to 17-year-olds); focuses on normative developmental outcomes; and includes multiple dimensions of neighborhoods and their associations with development via parental and family factors. A multigroup structural equation model (SEM, Figure 1) was used to examine the relations among dimensions of neighborhoods (neighborhood quality, resources, social cohesion, and safety), parenting and family factors (parenting stress, parental well-being, and parent-child interactions) and developmental outcomes (social adjustment and school engagement). 
International Journal of Child, Youth and Family Studies (2017) 8(3-4): 168-189

Given that NSCSP (Cantillon et al., 2003; Sun et al., 2004) have been found to be associated with parental and family well-being (Cuellar et al., 2015; Leventhal \& Brooks-Gunn, 2000; Tolan et al., 2003) and consequently children and adolescents' developmental outcomes (Booth et al., 2012; Caughy et al., 2012; Kohen et al., 2008; Vieno et al., 2010), several research questions are investigated:

1. How are distinct aspects of NSCSP associated with social adjustment and school engagement?

2. How are distinct aspects of NSCSP related to parental stress and well-being?

3. Are parental stress and well-being linked with family processes (i.e., parent-child interactions)?

4. Are family processes predictive of social adjustment and school engagement?

5. Does age moderate the associations linking NSCSP to developmental outcomes via parenting stress and well-being and family processes?

The solid and dotted lines in Figure 1 are representative of the effects of exogenous factors (predictors) on the endogenous ones (outcomes). The dotted lines are used to make it easier to read the model (they have the same meaning as the solid lines).

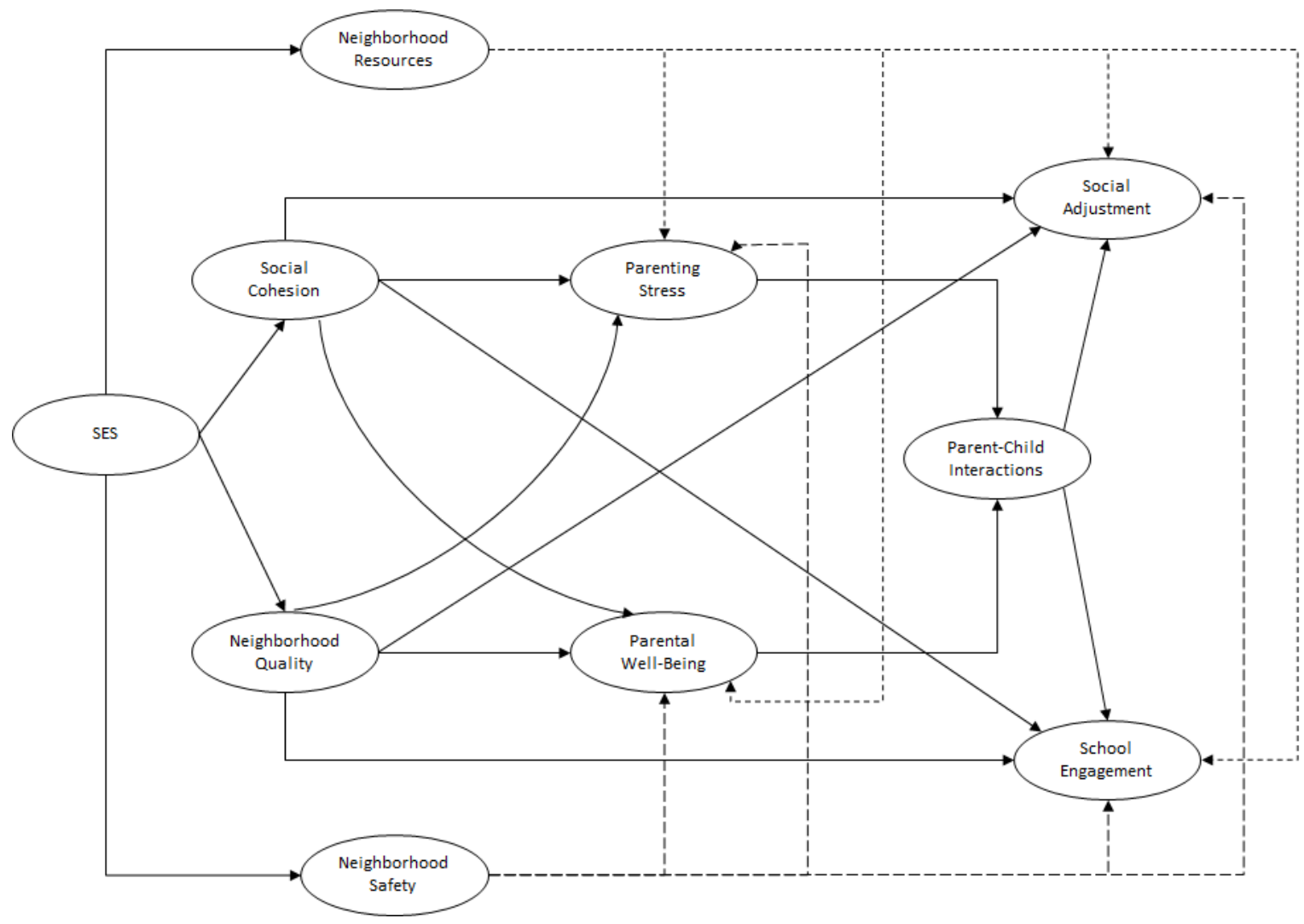

Figure 1. Model of associations among constructs. 
International Journal of Child, Youth and Family Studies (2017) 8(3-4): 168-189

\section{Methodology}

\section{Data and Sample}

Data used were taken from the National Survey of Children's Health (NSCH), 2007, a telephone survey sponsored by the Maternal and Child Health Bureau of the Health Resources and Services Administration, that intended to examine the physical and emotional health of children ages 0 to 17 (Child and Adolescent Mental Health Initiative, 2007). The survey emphasizes factors that may relate to well-being of children (Blumberg et al., 2012). The NSCH used the sampling frame from the National Immunization Survey, a large-scale random-digitdialed telephone survey designed to collect immunization history for children (Blumberg et al., 2012).

Computer-assisted telephone interviewing resulted in 91,642 completed child-level interviews. A letter was mailed prior to telephone calls. Potential responders used this number to alert interviewers that there were no children in their household, to ask questions about the study, or to complete an interview (Blumberg et al., 2012). Consent for participation was obtained when it was determined that a household contained an age-eligible child. The respondent was the adult in the household who was most knowledgeable about the sampled child's well-being (mother, father, or guardian). For the present study data on children ages 6 to $11(N=27,792)$ and adolescents ages 12-to-17 $(N=36,284)$ were used.

Table 1. Demographics and Socioeconomic Status by Age Group

\begin{tabular}{|c|c|c|c|c|}
\hline \multirow[b]{2}{*}{ Descriptive } & \multicolumn{2}{|c|}{$6-11$ years } & \multicolumn{2}{|c|}{$12-17$ years } \\
\hline & $n$ & $\%$ & $n$ & $\%$ \\
\hline \multicolumn{5}{|l|}{$\begin{array}{l}\text { Demographics } \\
\end{array}$} \\
\hline \multicolumn{5}{|l|}{ Race/Ethnicity } \\
\hline Hispanic & 3587 & $13.1 \%$ & 3770 & $10.6 \%$ \\
\hline White, non-Hispanic & 18420 & $67.4 \%$ & 25369 & $71.1 \%$ \\
\hline African American, non-Hispanic & 2740 & $10.0 \%$ & 3710 & $10.4 \%$ \\
\hline Multi/Other, non-Hispanic & 2565 & $9.4 \%$ & 2824 & $7.9 \%$ \\
\hline \multicolumn{5}{|l|}{ Family type } \\
\hline Two parent, biological or adopted & 19128 & $69.3 \%$ & 22910 & $63.5 \%$ \\
\hline Two parent, step family & 2098 & $7.6 \%$ & 3974 & $11.0 \%$ \\
\hline Single mother, no father present & 4502 & $16.3 \%$ & 6421 & $17.8 \%$ \\
\hline Other family type & 1893 & $6.9 \%$ & 2755 & $7.6 \%$ \\
\hline \multicolumn{5}{|l|}{ Sex of child } \\
\hline Male & 14323 & $51.6 \%$ & 18969 & $52.4 \%$ \\
\hline Female & 13429 & $48.4 \%$ & 17264 & $47.6 \%$ \\
\hline \multicolumn{5}{|l|}{ Socioeconomic status } \\
\hline \multicolumn{5}{|l|}{ Income-Poverty } \\
\hline 0-99\% FPL & 3365 & $12.1 \%$ & 3673 & $10.1 \%$ \\
\hline 100-199\% FPL & 4904 & $17.6 \%$ & 5739 & $15.8 \%$ \\
\hline 200-399\% FPL & 9594 & $34.5 \%$ & 12272 & $33.8 \%$ \\
\hline $400 \%$ FPL or greater & 9929 & $35.7 \%$ & 14600 & $40.2 \%$ \\
\hline \multicolumn{5}{|l|}{ Parental Education } \\
\hline Less than high school & 1989 & $7.8 \%$ & 2617 & $7.9 \%$ \\
\hline 12 years/high school graduate & 5030 & $19.7 \%$ & 7352 & $22.2 \%$ \\
\hline More than high school & 18575 & $72.6 \%$ & 23180 & $69.9 \%$ \\
\hline
\end{tabular}


International Journal of Child, Youth and Family Studies (2017) 8(3-4): 168-189

Table 2. Socioeconomic Status, Neighbourhood, Parenting, and Schooling by Age Group

\begin{tabular}{|c|c|c|c|c|c|c|}
\hline \multirow[b]{2}{*}{ Descriptive } & \multicolumn{3}{|c|}{$6-11$ years } & \multicolumn{3}{|c|}{$12-17$ years } \\
\hline & $M$ & $S D$ & $n$ & $M$ & $S D$ & $n$ \\
\hline \multicolumn{7}{|l|}{ Socioeconomic status } \\
\hline Past year - employed 50 weeks or more & .91 & .28 & 27458 & .91 & .29 & 35861 \\
\hline \multicolumn{7}{|l|}{ Neighborhood resources } \\
\hline Sidewalks, walking paths exist in your neighborhood & 0.70 & 0.46 & 27538 & 0.70 & 0.46 & 35954 \\
\hline Parks or playgrounds & 0.80 & 0.40 & 27538 & 0.77 & 0.42 & 35960 \\
\hline Recreation, community center or clubs & 0.65 & 0.48 & 27130 & 0.64 & 0.48 & 35604 \\
\hline Library or bookmobile & 0.88 & 0.33 & 27495 & 0.87 & 0.34 & 35923 \\
\hline \multicolumn{7}{|l|}{ Neighborhood quality } \\
\hline Litter or garbage in street or sidewalks & 0.16 & 0.36 & 27525 & 0.15 & 0.35 & 35952 \\
\hline Poorly kept or rundown housing & 0.14 & 0.34 & 27493 & 0.14 & 0.35 & 35904 \\
\hline Vandalism - broken glass or graffiti & 0.10 & 0.29 & 27522 & 0.10 & 0.30 & 35945 \\
\hline \multicolumn{7}{|l|}{ Neighborhood safety } \\
\hline Feel safe in community in the neighborhood & 3.40 & 0.74 & 27482 & 3.45 & 0.70 & 35902 \\
\hline Feel safe at school & 3.63 & 0.60 & 26804 & 3.41 & 0.69 & 34960 \\
\hline \multicolumn{7}{|l|}{ Neighborhood social cohesion } \\
\hline People in neighborhood help each other out & 3.36 & 0.74 & 27270 & 3.34 & 0.74 & 35605 \\
\hline We watch out for each other's children & 3.49 & 0.75 & 27238 & 3.46 & 0.75 & 35533 \\
\hline There are people I can count on & 3.55 & 0.77 & 27310 & 3.55 & 0.76 & 35655 \\
\hline Adults nearby whom I trust to help & 3.62 & 0.73 & 27295 & 3.64 & 0.69 & 35634 \\
\hline \multicolumn{7}{|l|}{ Parenting stress } \\
\hline Coping with the demands of day-to-day parenting & 1.43 & 0.53 & 27701 & 1.47 & 0.55 & 36153 \\
\hline Child much harder to care for than most children & 1.52 & 0.81 & 27031 & 1.58 & 0.85 & 35121 \\
\hline Does things that really bother you a lot & 2.03 & 0.82 & 27404 & 2.10 & 0.83 & 35579 \\
\hline How often felt angry with child & 2.16 & 0.73 & 27594 & 2.16 & 0.75 & 35963 \\
\hline \multicolumn{7}{|l|}{ Parental well-being } \\
\hline General health status of mother & 2.10 & 0.97 & 25793 & 2.21 & 1.02 & 33371 \\
\hline Mothers mental and emotional health & 1.96 & 0.89 & 25765 & 2.01 & 0.92 & 33353 \\
\hline \multicolumn{7}{|l|}{ Parent-child interactions } \\
\hline Frequency of attendance at child events past 12 months & 3.59 & 0.68 & 23667 & 3.39 & 0.81 & 31304 \\
\hline How well talk about things that matter & 3.75 & 0.49 & 27728 & 3.60 & 0.58 & 36220 \\
\hline \multicolumn{7}{|l|}{ School Engagement } \\
\hline Cares about doing well in school & 4.55 & 0.72 & 27742 & 4.37 & 0.88 & 36225 \\
\hline Does all required homework & 4.62 & 0.68 & 27678 & 4.28 & 0.90 & 36203 \\
\hline \multicolumn{7}{|l|}{ Social Adjustment } \\
\hline Shows respect for teachers and neighbors & 4.68 & 0.61 & 27776 & 4.61 & 0.68 & 36251 \\
\hline Gets along well with other children & 4.42 & 0.67 & 27779 & 4.48 & 0.67 & 36251 \\
\hline Tries to understand other people's feelings & 4.13 & 0.86 & 27734 & 4.09 & 0.90 & 36210 \\
\hline Tries to resolve conflicts with classmates, family, or friends & 3.92 & 0.95 & 27648 & 3.99 & 0.95 & 36060 \\
\hline
\end{tabular}


International Journal of Child, Youth and Family Studies (2017) 8(3-4): 168-189

\section{Measures}

Socioeconomic status (SES): Used as a covariate, this latent construct was assessed with three items: anyone in the household employed at least 50 weeks $(0=$ no, $1=$ yes $)$, income-poverty partitioned into eight levels based on the U.S. Department of Health and Human Services guidelines $(0$ $=$ at or below $100 \%$ of poverty to $8=$ above $400 \%$ poverty level), and parental education categorized into three levels $(0=$ less than high school to $3=$ more than high school).

\section{Perceptions of Neighborhood Structural Characteristics and Social Processes (NSCSP)}

Subjective questions were used to assess the distinct dimensions of NSCSP. Subjective assessments are advantageous over aggregate census data because they examine respondents own perceptions and focus on aspects of the neighborhood that may be salient to respondents (Cummins, Macintyre, Davidson, \& Ellaway, 2005). As well, aggregate data may not accurately reflect neighborhoods as experienced by residents as conditions may change between periods of collecting aggregate data (Hadley-Ives et al., 2000).

Neighborhood resources: Neighborhood physical resources, such as libraries and parks, have been found to contribute to healthy development (Anthony \& Nicotera, 2008) and play a role in shaping observations and interactions with other residents (Curley, 2010). Four items asking about the availability or presence of: (a) sidewalks or walking paths, (b) parks of playgrounds, (c) recreation, community center, or clubs, and (d) library or bookmobile were used as indicators of the latent construct of neighborhood resources. These items have been found to be a reliable means to assess the physical environment (Echeverria, Diez-Roux, \& Link, 2004; Ross \& Mirowsky, 2001). Questions were answered no (0) or yes (1).

Neighborhood quality: Objective, aggregate data like crime rates do not measure the quality of neighborhood life as experienced by residents (Buron \& Patrabansh, 2008; Mast, 2010). The construct of neighborhood quality was indicated by three questions answered no (0) or yes (1) that asked about the following: (a) litter or garbage in street or sidewalks, (b) poorly kept or rundown housing, and (c) vandalism - broken window glass or graffiti in the neighborhood. These items have been used in prior research and found to be associated with increased crime (Coulton, Pandey, \& Chow, 1990; HadleyIves et al., 2000) and adverse developmental outcomes (Coley, Leventhal, Lynch, \& Kull, 2013). Higher scores indicate a perception of poorer neighborhood quality.

Neighborhood safety: Survey questionnaires that measure respondents' assessments of their neighborhood have been used (Booth et al., 2012; Molnar, Gortmaker, Bull, \& Buka, 2004), and found to be reliable and to be associated with objective indicators of neighborhood safety (Echeverria et al., 2004). Two questions that asked about (a) feelings of safety in community or the neighborhood and (b) feeling safe at school were used to indicate this latent construct. These questions were answered on a 4point scale, from 1 (never) to 4 (always). Higher scores indicate feelings of safety.

Neighborhood social cohesion: The items included in the construct are indicative of the expectation of the willingness of neighborhood residents to act in support of each other (Larsen, 2013; Sampson et al., 1997, 1999), a sense of trust, and the extent to which neighbors help each other 
International Journal of Child, Youth and Family Studies (2017) 8(3-4): 168-189

(Larsen, 2013; Henry, Gorman-Smith, Schoeny, \& Tolan, 2014). The questions used as indicators of social cohesion asked respondents their level of agreement with the following statements: (a) people in the neighborhood help each other out, (b) we watch out for each other's children, (c) there are people I can count on, and (d) there are adults nearby whom I trust to help. The responses, on a 4-point scale were reverse-coded, from 1 (definitely disagree), to 4 (definitely agree), such that a higher score represents increased neighborhood social cohesion.

\section{Perceptions of Parenting and Family Constructs}

Parenting stress: Parenting stress was assessed with four questions that asked about the parenting experiences and the negative impact of the focal child on feelings about parenting (Abidin, 2012). Thus, there is an implication that challenges presented by the child are associated with parenting stress (Baker et al., 2003). The questions asked about (a) coping with the demands of day-to-day parenting, (b) if child is much harder to care for than most children, (c) if child does things that really bother parent a lot, and (d) how often parent felt angry with child. These four questions were answered on a 4-point scale ranging from 1 (very well) to 4 (not very well at all). Higher scores indicate increased parenting stress.

Parental well-being: Two questions that asked about (a) parental emotional and mental health and (b) the general health status of parent were used to indicate this factor. Parents rated their emotional and mental and physical health on a 5-point scale ranging from 1 (excellent) to 5 (poor). Higher scores indicate poorer parental well-being.

Parent-child interactions: The items loaded on this factor can be said to represent elements of parental monitoring, investment, and warmth - a proxy for family processes (Cuellar et al., 2015); and involves sensitivity to the child's interest and affect, and active participation on the part of the parent (Rosenberg, Robinson \& Beck, 1986). The two questions asked were: (a) frequency of parental attendance at child events past 12 months, rated on a 4-point scale from 1 (never) to 4 (always), and (b) how well parent and child talk about things that matter, reverse-coded on a scale from 1 (not very well at all) to 4 (very well). Higher ratings are indicative of more positive parent-child interactions.

\section{Perceptions of Psychosocial and Academic Outcomes}

Social Adjustment: This is a global and multifaceted construct, and can be conceptualized as the ability to get along with others and be liked (Blumberg, Carle, O'Connor, Moore, \& Lippman, 2008). Behaviors indicative of social adjustment occur in particular contexts (Oppenheimer, 1988); thus, it is important to assess multiple competencies: affective (understanding others' feelings), behavioral (getting along with others), and cognitive (conflict resolution; Blumberg et al., 2008; Caplan $\&$ Weissberg, 1988). Four questions were used to indicate social adjustment: (a) child shows respect for teachers and neighbors, (b) child gets along well with other children, (c) child tries to understand other people's feelings, and (d) child tries to resolve conflicts with classmates, family, or friends. These questions were answered on a 5-point scale, ranging from 1 (never) to 5 (always). Higher ratings indicate an increased display of socially competent behaviors. 
International Journal of Child, Youth and Family Studies (2017) 8(3-4): 168-189

School Engagement: Two aspects of school engagement were assessed: behavioral and cognitive (Fredricks, Blumenfeld, \& Paris, 2004). Behavioral engagement involves participation in school-related activities and involvement in academic or learning tasks, whereas cognitive engagement consists of an investment in learning and a desire to master difficult skills (Fredricks et al., 2004). School engagement was indicated by two questions: (a) child cares about doing well in school, and (b) child does all required homework, responded to on a 5-point scale ranging from 1 (never) to 5 (always). Higher ratings indicate increased levels of engagement.

Two caveats regarding the measures used in the present study are in order. First, the questions or items used to measure the different constructs in this study are limited in scope (not broad enough); the narrow focus of these items enables the assessment of large samples in a large nationally representative survey. That, however, has the disadvantage of not being able to capture all aspects that may be germane to each construct. Second, as is common with most large surveys that aim to be nationally representative, the data comes from a single source - parents or guardians of children and adolescents. Thus, as the accuracy of results depends on the extent to which parents or guardians are accurate in their descriptions of children and adolescents experiences, this study may suffer from a single source bias.

\section{Analytic Approach}

A multigroup SEM was conducted using AMOS 16.0 program with maximum likelihood estimation procedures (Arbuckle, 2005). A three-step analysis was used to examine three issues: configural, measurement, and structural invariance. In terms of configural invariance, the question investigated was: Is the structural pattern of causal associations among the constructs similar for children and adolescents? The issues of measurement (factorial) and structural invariance assessed whether or not parts of the measurement model, structural model, or both were invariant across agegroups. The unconstrained full model (step 1) was used as a baseline model against which ensuing (nested) models in steps 2 to 3 were compared using the chi-square $\left(\chi^{2}\right)$ difference test (a significant $\chi^{2}$ means the groups differ in some manner; Byrne, 2001). In step 2 (invariant factor weights), all the factor loadings were constrained equal across groups, and the fit of this model was then compared to the baseline model. In step 3 (invariant structural weights) cross-group equality constraints were imposed on structural paths, and the fit of this model was then compared to the baseline model. These steps (2 to 3 ) are analogous to testing for moderation effects in multiple regression.

The $\chi^{2}$ statistic was used to assess overall model fit; however, the $\chi^{2}$ value is affected by sample size increasing the likelihood that a target model would be rejected. But, a significant $\chi^{2}$ is not a reason by itself to modify a model; alternative fit indices have to be considered to determine if they provide a good fit to the data (Kline, 1998). Consequently, the comparative fit index (CFI), the root mean square error of approximation (RMSEA), and probability of close fit (PCLOSE) were used to augment the $\chi^{2}$ index. For a good fit, Hu and Bentler (1999) suggested a CFI value of at least .95 and RMSEA of $p<$ .06; and Loehlin (1998) argued for PCLOSE of $p>.05$. MacCallum, Browne, and Sugawara (1996) have used RMSEA values of .01, .05, and .08 to indicate excellent, good, and mediocre fit, respectively. Marsh, Hau, and Wen (2004) contend that there is no golden criteria for cutoff values for fit indices, consequently, multiple criteria should be used. 
International Journal of Child, Youth and Family Studies (2017) 8(3-4): 168-189

\section{Results}

\section{Configural Invariance (Baseline) Model}

The baseline model was used to investigate whether the associations among the latent constructs in the hypothesized model were equivalent across age groups (6-11 years vs. 12-17 years; see Tables $3 \& 4)$. Given the large sample size, the chi-square test $\left(\chi^{2}[746, N=63,985]=33912.05, p\right.$ $<.001 ;$ CFI = .92; RMSEA = .026; PCLOSE = 1.00; see Model 1, Table 3) showed that the model differed slightly from the data. Also, the CFI value was slightly less than the recommended .95. However both the RMSEA and PCLOSE values suggest that model is reasonably consistent with the data (that is, has a good fit), which implies that the pattern of factor loadings and structural associations among the latent constructs is reasonable. The constructs in the model (see Figure 2) explained $65 \%$ of the variation in perceived social adjustment for children and $63 \%$ for adolescents. Where school engagement was concerned, the factors explained $44 \%$ of the variation for children and $37 \%$ for adolescents.

Table 3 Goodness-of-fit Tests

\begin{tabular}{lccccccc}
\hline & \multicolumn{3}{c}{ Goodness of fit } & \multicolumn{3}{c}{ Test of close fit } \\
\cline { 2 - 7 } Modeling Steps/Labels & $D f$ & $\chi^{2}$ & $p$ & CFI & RMSEA & PCLOSE \\
\hline Model 1: Unconstrained model & 746 & 33912.05 & $<.001$ & 0.92 & 0.026 & 1.00 \\
Model 2: Invariant factor weights & 766 & 34413.66 & $<.001$ & 0.92 & 0.026 & 1.00 \\
Model 3: Invariant structural weights & 790 & 34859.53 & $<.001$ & 0.92 & 0.026 & 1.00 \\
\hline
\end{tabular}

Table 4 Comparsion of Model 1 with Model 2 and Model 3

\begin{tabular}{lccc}
\hline \multirow{2}{*}{ Models } & \multicolumn{4}{c}{ Comparative Test of Fit } \\
\cline { 2 - 4 } & $\Delta d f$ & $\Delta \chi^{2}$ & $p(\mathrm{~d})$ \\
\hline Model 2 versus Model 1 & 20 & 501.61 & $<.001$ \\
Model 3 versus Model 1 & 44 & 947.48 & $<.001$ \\
\hline
\end{tabular}

\section{Covariate (SES) Effects}

For both children and adolescents, higher SES was positively associated with perceptions of increased levels of neighborhood resources (children: $\beta=.16$; adolescents: $\beta=.13$ ), social cohesion (children: $\beta=.28$; adolescents: $\beta=.27$ ), and neighborhood safety (children: $\beta=.23$; adolescents: $\beta=$ .27 ), and negatively with poorer neighborhood quality (children: $\beta=-.32$; adolescents: $\beta=-.33$ ). A comparison of unstandardized coefficients suggested that the effect of SES on perceptions of neighborhood safety was stronger for adolescents than for children. 


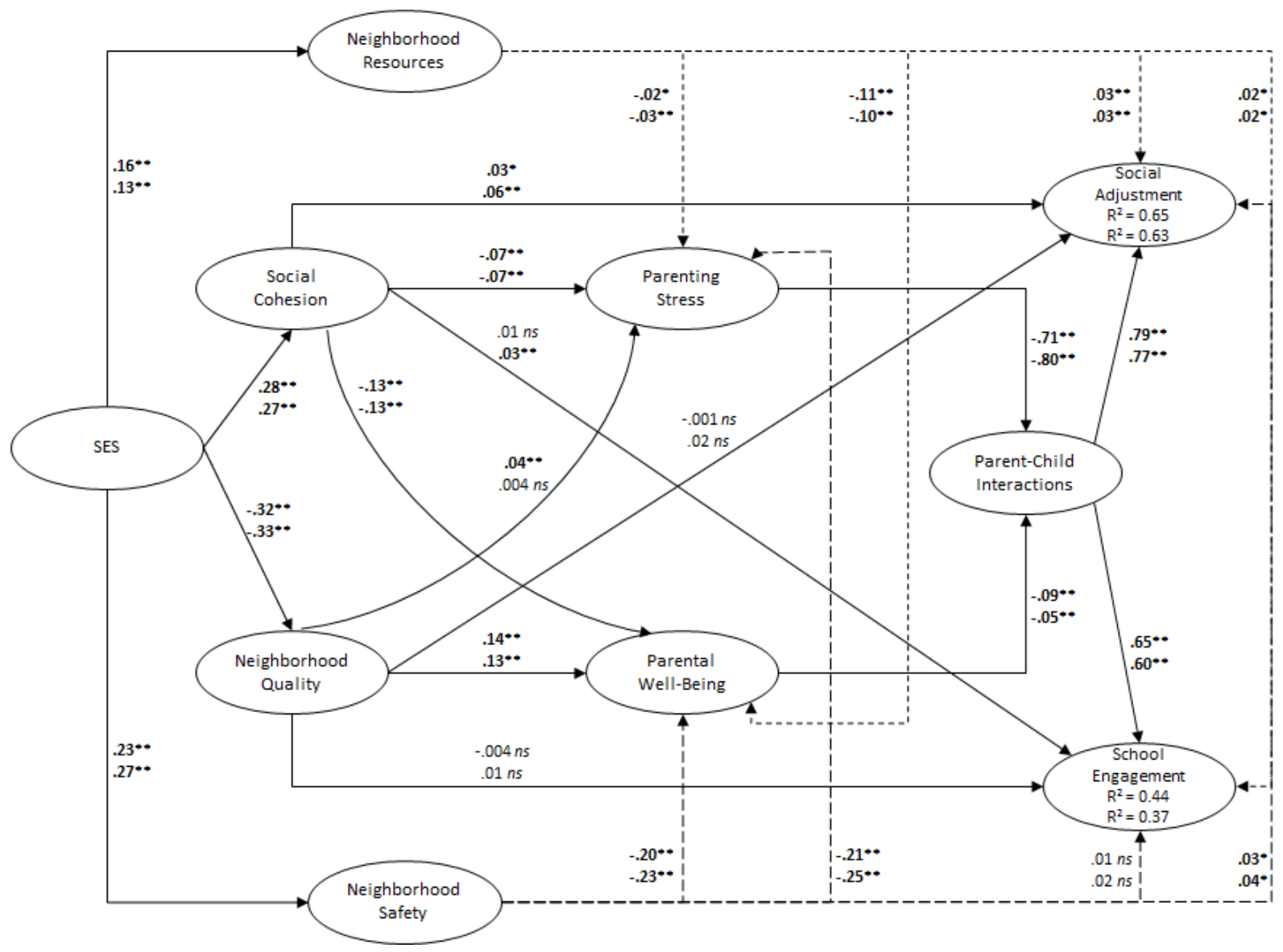

Figure 2. Model of associations among constructs for children (ages 6-11) and adolescents (ages 1217). Standardized coefficients (top for children and bottom for adolescents) and $R^{2}$ for outcomes are reported.

$* p<.05, * * p<.01$.

The results focus on perceptions of parents (or guardians) regarding NSCSP, the stress associated with parenting and their own well-being, as well as the quality of parent-child relations and child outcomes. To limit the repetition of the words "perception" and "perceived", all constructs are to be understood as based on parental or guardian perceptions only, and not on objective measures or information from multiple sources. Results for research question 5, which deals with the moderation of pathways by age, are included in the discussion of results for research questions 1 through 4 .

Research questions 1 and 2: Associations of NSCSP with parental stress and well-being, and with social adjustment and school engagement, are shown in Figure 2. Increased neighborhood resources was negatively associated with higher levels of parenting stress (children: $\beta=-.02$; adolescents: $\beta=-.03$ ) and poorer parental well-being (children: $\beta=-.11$; adolescents: $\beta=-.10$ ), and positively associated with higher levels of social adjustment (children: $\beta=.03$; adolescents: $\beta=.03$ ) and school engagement (children: $\beta=.02$; adolescents: $\beta=.02$ ). Higher levels of neighborhood social cohesion were negatively associated with higher levels of parenting stress (children: $\beta=-.07$; adolescents: $\beta=-.07$ ) and poorer parental well-being (children: $\beta=-.13$; adolescents: $\beta=-.13$ ). However, the positive relations between higher levels of neighborhood social cohesion and social 
International Journal of Child, Youth and Family Studies (2017) 8(3-4): 168-189

adjustment (children: $\beta=.03$; adolescents: $\beta=.06$ ) and school engagement (children: $\beta=.01, n s$; adolescents: $\beta=.03)$ were a bit weaker for children than for adolescents $(z=-2.82, p<.01)$ and $(z=$ $-2.68, p<.01)$, respectively.

For children $(\beta=.04)$, but not adolescents $(\beta=.0004, n s)$, poorer neighborhood quality was associated with increased levels of parenting stress; for both children and adolescents, poorer neighborhood quality was correlated with poorer parental well-being (children: $\beta=.14$; adolescents: $\beta$ $=.13$ ). The associations between poorer neighborhood quality and social adjustment (children: $\beta=$ $-.001, n s$; adolescents: $\beta=.02, n s$ ) and school engagement (children: $\beta=-.004$, ns; adolescents: $\beta=$ $.01, n s)$ were non-significant, but also reversed the direction of coefficient for adolescents only. Increased neighborhood safety was negatively associated with higher levels of parenting stress (children: $\beta=-.21$; adolescents: $\beta=-.25$ ) and poorer parental well-being (children: $\beta=-.20$; adolescents: $\beta=-.23$ ), but was positively associated with social adjustment (children: $\beta=.03$; adolescents: $\beta=.04$ ), and had no significant association with school engagement (children: $\beta=.01, n s$; adolescents: $\beta=.02, n s)$.

Research questions 3 and 4: Associations of parental stress and well-being with parent-child relations, and of parent-child relations with social adjustment and school engagement are shown in Figure 2. Higher levels of parenting stress were negatively associated with better parent-child relations (children: $\beta=-.71$; adolescents: $\beta=-.80$ ), but the effects were weaker for children compared with adolescents $(z=-9.55, p<.001)$. Poorer parental well-being was negatively associated with better parent-child interactions (children: $\beta=-.09$; adolescents: $\beta=-.05$ ), but the effects were stronger for children than for adolescents $(z=2.34, p<.01)$. Better parent-child interactions were associated with an increase in social adjustment (children: $\beta=.79$; adolescents: $\beta=.77$ ) and school engagement (children: $\beta=.65$; adolescents: $\beta=.60$ ). However, the effect of parent-child interactions on social adjustment was stronger for children than for adolescents $(z=8.11, p<.001)$, whereas its effect on school engagement was stronger for adolescents than for children $(z=9.33, p<.001)$.

\section{Discussion and Conclusion}

The current study used data from a national sample of children and adolescents to investigate the processes through which NSCSP are correlated with children and adolescents' social adjustment and school engagement via parental stress and well-being and family processes. Integrating ideas from social disorganization theory, family stress theory, and environmental psychology, several questions were investigated: how are distinct aspects of NSCSP associated with parental stress and well-being, and with youth social adjustment and school engagement? Are parental stress and well-being linked with family processes, and are family processes predictive of youth social adjustment and school engagement? Finally, does age moderate the associations linking NSCSP to perceived developmental

outcomes via parenting stress, parental well-being, and family processes? In totality, the findings supported the hypothesized pathways, after adjusting for the effects of SES. Higher SES was associated with perceptions of increased levels of neighborhood resources, social cohesion, and neighborhood safety, but negatively with poorer neighborhood quality. These findings suggest that higher SES affects the resources neighborhoods have (e.g., parks or libraries), and the social cohesion and sense of safety 
International Journal of Child, Youth and Family Studies (2017) 8(3-4): 168-189

experienced by residents. Conversely, those with higher SES are less likely to reside in neighborhoods that experience physical decay (litter or garbage in the street or on the sidewalk, or poorly kept or rundown housing).

In regard to the questions investigated: First, increased levels of neighborhood resources, social cohesion, and safety (but not neighborhood quality) were directly associated with higher scores on perceived social adjustment; the effects of social cohesion on perceived social adjustment and school engagement were stronger for adolescents than they were for children. Second, higher levels of neighborhood resources, but not neighborhood quality or safety, were directly correlated with higher ratings on school engagement for children and adolescents. These patterns of findings, in relation to how distinct aspects of NSCSP were related to perceived social adjustment and school engagement, suggest that it is important to parse out contextual factors to understand their unique associations with different developmental outcomes. Furthermore, the observed moderation effect between neighborhood social cohesion on the one hand, and perceived social adjustment and school engagement on the other, suggests that effects of neighborhood social cohesion on developmental outcomes may vary based on individual characteristics. Specifically, the level of social cohesion of a neighborhood may be more beneficial to the perceived social adjustment and academic outcomes of adolescents compared with children. That may be the case because neighbors are more likely to assist and intervene before adolescent issues get out of hand (Byrnes et al., 2013; Cantillon, 2006). Additionally, the lack of significant direct associations (noted previously) could also indicate that the paths between these factors and perceived developmental outcomes were fully mediated by parenting stress, parental wellbeing, and parent-child interactions (Baron \& Kenny, 1986). Together, these results provide support for the extant literature linking NSCSP to developmental outcomes (Caughy et al., 2012; Kohen et al., 2008; McNulty \& Bellair, 2003; Tolan et al., 2003)

In relation to the effects of NSCSP on parenting, higher levels of neighborhood resources, social cohesion, and perception of neighborhood safety were associated with lower levels of parenting stress and better parental well-being, whereas poorer neighborhood quality was linked with higher levels of parenting stress and poorer parental well-being. These results are consistent with evidence from other researchers showing that the structural characteristics and social processes of neighborhoods can have an effect on parental functioning and well-being (Chung \& Steinberg, 2006; Kohen et al., 2008; Kotchick et al., 2005; Law \& Barber, 2007; White et al., 2009). Higher levels of parenting stress and poorer parental well-being were associated with poorer parent-child relations. However, the effect of higher levels of parenting stress on parent-child interactions was stronger for adolescents than for children. Conversely, the effect of poorer parental well-being on better parent-child relations was stronger for children than for adolescents. Furthermore, better parent-child interactions were associated with perceived improvements in social adjustment and higher levels of school engagement. But the association between better parent-child interactions and perceived social adjustment was stronger for children than for adolescents, whereas the effect of better parent-child interactions on higher levels of school engagement was stronger for adolescents than for children.

These findings, in concert, are consistent with research on economic distress (Conger et al., 1992; Gonzales et al., 2011; Kohen et al., 2008; Kotchick et al., 2005; McLoyd, 1990) and 
neighborhood disadvantage (Chung \& Steinberg, 2006; McNulty \& Bellair, 2003; Tolan et al., 2003) and their impacts on parenting and family functioning. Specifically, these lines of evidence suggest that economic or neighborhood structural disadvantages place parents under increased stress, thus compromising their emotional well-being. Additionally, parental stress and emotional difficulties are detrimental to family functioning, with adverse effects on youth development (Conger et al., 1992; Gonzales et al., 2011; McLoyd, 1990; McNulty \& Bellair, 2003; Tolan et al., 2003). Consistent with Bronfenbrenner and Ceci's (1994) and Bronfenbrenner and Evans' (2000) contention that the parental and family context interacts with child characteristics to influence developmental outcomes, the present study found that (a) the effects of higher levels of parental stress compromise positive parent-child interactions to a greater extent among adolescents than among children; (b) the effects of diminished parental well-being on positive parent-child interactions had a stronger adverse impact on perceived well-being of children compared to adolescents; (c) the effects of higher levels of parent-child interactions on perceived social adjustment were stronger for children than for adolescents; and (d) the effects of higher levels of parent-child interactions on increased school engagement were stronger for adolescents than for children.

Although the present study adds to the existing literature, there are some limitations worth noting. First, because the study was a secondary analysis of survey data, it suffers from the limitations one usually encounters when using pre-existing data. For example, NSCH was not designed to measure parent-child interactions in their entirety; consequently, the construct of parent-child interactions utilized in the study fails to capture many relevant dimensions. Second, the study suffers from having a single source of information: all measures used in the study were provided by parents. As a corollary, the constructs were measured at the individual level, so may not reflect aggregate measures of NSCSP. Third, the study was cross-sectional, thus it cannot address issues related to the direction of effects; specifically, how NSCSP influence development. The study did not consider reciprocal effects between parenting and perception of child outcomes, nor can it rule out the possibility that constructs omitted from the model, or equivalent models with different variables and links, could also account for the variation observed (Raykov \& Penev, 1999). Given these limitations, it would be of interest to examine the model using aggregated measures of NSCSP to determine whether the findings are supported.

Notwithstanding these limitations, this study investigated the associations among perceptions of NSCSP, parenting and parent-child interactions, and children and adolescents' social adjustment and school engagement in a way not previously tried. Specifically, it examined how distinct aspects of NSCSP were associated with positive developmental outcomes via parenting stress, parental wellbeing, and parent-child interactions. This study contributes to the literature by focusing on positive developmental outcomes, and reveals that the effects of NSCSP on development may be diverse rather than singular: these associations are mediated by parenting stress, parental well-being, and family processes, and moderated by the age of the child. The results presented in this study have implications for programs or interventions that are directed toward families; they suggest that such programs should also focus on dimensions of the neighborhood or context because of their salutary effects on ameliorating parental stress, improving parental well-being, and consequently parent-child interactions, which ultimately impacts the developmental outcomes of youth. 
International Journal of Child, Youth and Family Studies (2017) 8(3-4): 168-189

\section{References}

Abidin, R. R. (2012). Parenting stress index (4th ed.). Lutz, FL: PAR - Psychological Assessment Resources.

Anthony, E. K., \& Nicotera, N. (2008). Youth perceptions of neighborhood hassles and resources: A mixed method analysis. Children and Youth Services Review, 30, 1246-1255. doi:10.1016/j.childyouth.2008.03.009

Arbuckle, J. L. (2005). AMOS 6.0 users guide. Spring House, PA: Amos Development Corporation.

Arnsten, A. F. T. (2009). Stress signaling pathways that impair prefrontal cortex structure and function. Nature Reviews Neuroscience, 10, 410-422. doi:10.1038/nrn2648

Baker, B. L., McIntyre, L. L., Blacher, J. Crnic, K., Edelbrock, C., \& Low, C. (2003). Pre-school children with and without developmental delay: Behaviour problems and parenting stress over time. Journal of Intellectual Disability Research, 47(Part 4/5), 217-230. doi:10.1046/j.1365$\underline{2788.2003 .00484 . x}$

Baron, R. M., \& Kenny, D. A. (1986). The moderator-mediator variable distinction in social psychological research: Conceptual, strategic and statistical considerations. Journal of Personality and Social Psychology, 51, 1173-1182.

Berenson, A. B., Wiemann, C., \& McCombs, S. (2001). Exposure to violence and associated healthrisk behaviors among adolescent girls. Archives of Pediatrics and Adolescent Medicine, 155, $1238-1242$.

Blumberg, S. J., Carle, A. C., O’Connor, K. S., Moore, K. A., \& Lippman, L. H. (2008). Social competence: Development of an indicator for children and adolescents. Child Indicators Research, 1, 176-197. doi:10.1007/s12187-007-9007-x

Blumberg, S. J., Foster, E. B., Frasier, A. M., Satorius, J., Skalland, B. J., Nysse-Carris, K. L., ... O'Connor, K. S. (2012). Design and operation of the National Survey of Children's Health, 2007 [Issue 55 of Vital Health and Statistics, Programs and Collections Procedures]. Hyattsville, MD: National Center for Health Statistics. Retrieved from https://www.cdc.gov/nchs/data/series/sr_01/sr01_055.pdf

Booth, J., Ayers, S. L., \& Marsiglia, F. F. (2012). Perceived neighborhood safety and psychological distress: Exploring protective factors. Journal of Sociology and Social Work, 39(4), 137-156. Retrieved from http://scholarworks.wmich.edu/jssw/vol39/iss4/8

Bronfenbrenner, U., \& Ceci, S. J. (1994). Nature-nurture reconceptualized in developmental perspective: A bioecological model. Psychological Review, 101, 568-586. doi:10.1037/0033295X.101.4.568 
International Journal of Child, Youth and Family Studies (2017) 8(3-4): 168-189

Bronfenbrenner, U., \& Evans, G. W. (2000). Developmental science in the 21st century: Emerging questions, theoretical models, research designs, and empirical findings. Social Development, 9 , 115-125. doi:10.1111/1467-9507.00114

Buron, L., \& Patrabansh, S. (2008). Are census variables highly correlated with housing choice voucher holders' perception of the quality of their neighborhoods? Cityscape: A Journal of Policy Development and Research 10(1), 157-183.

Bursik, R. J., \& Grasmick, H. G. (1996). Neighbourhood-based networks and the control of crime and delinquency. In H. Barlow (Ed.), Crime and Public Policy (pp. 107-130). Boulder, CO: Westview.

Byrne, B. M. (2001). Structural equaling modeling with AMOS: Basic concepts, applications, and programming. Mahwah, NJ: Lawrence Erlbaum Associates.

Byrnes, H. F., Miller, B. A., Chamratrithirong, A., Rhucharoenpornpanich, O., Cupp, P. K., Atwood, K. A., ... Chookhare, W. (2013). The roles of perceived neighborhood disorganization, social cohesion, and social control in urban Thai adolescents' substance use and delinquency. Youth \& Society, 45(3), 404-427. doi:10.1177/0044118X11421940

Cantillon, D. (2006). Community social organization, parents, and peers as mediators of perceived neighborhood block characteristics on delinquent and prosocial activities. American Journal of Community Psychology, 37(1-2), 111-127. doi:10.1007/s10464-005-9000-9

Cantillon, D., Davidson, W. S., \& Schweitzer, J. H. (2003). Measuring community social organization: Sense of community as a mediator in social disorganization theory. Journal of Criminal Justice, 31(4), 321-339. doi:10.1016/S0047-2352(03)00026-6

Caplan, M. Z., \& Weissberg, R. P (1988). Promoting social competence in early adolescence:

Developmental considerations. In B. H. Schneider, G. Attili, J. Nadel, \& R. P. Weissberg (Eds.), Social competence in developmental perspective (pp. 371-386). Boston, MA: Kluwer Academic.

Caughy, M. O., Franzini, L., Windle, M., Dittus, P., Cuccaro, P., Elliott, M. N., \& Schuster, M. A. (2012). Social competence in late elementary school: Relationships to parenting and neighborhood context. Journal of Youth and Adolescence, 41, 1613-1627. doi:10.1007/s10964-012-9779-2

Ceballo, R., \& McLoyd, V. C. (2002). Social support and parenting in poor, dangerous neighborhoods. Child Development, 73(4), 1310-1321. doi:10.1111/1467-8624.00473

Child and Adolescent Health Measurement Initiative. (2007). DRC indicator dataset: 2007 National Survey of Children's Health. Data Resource Center for Child and Adolescent Health. Retrieved from http://www.childhealthdata.org

Chung, H. E., \& Steinberg, L. (2006). Relations between neighborhood factors, parenting behaviors, peer deviance, and delinquency among serious juvenile offenders. Developmental Psychology, 42(2), 319-331. doi:10.1037/0012-1649.42.2.319 
International Journal of Child, Youth and Family Studies (2017) 8(3-4): 168-189

Coley, R. L., Leventhal, T., Lynch, A. D., \& Kull, M. (2013). Relations between housing characteristics and the well-being of low-income children and adolescents. Developmental Psychology, 49(9), 1775-89. doi:10.1037/a0031033

Conger, R. D., Conger, K. J., Elder, G. H., Jr., Lorenz, F. O., Simons, R. L., \& Whitbeck, L. B. (1992). A family process model of economic hardship and adjustment of early adolescent boys. Child Development, 63(3), 526-541. doi:10.1111/j.1467-8624.1992.tb01644.x

Conger, R. D., \& Elder, G. H. (1994). Families in troubled times: Adapting to change in rural America. New York, NY: Aldine De Gruyter.

Cooley-Quille, M., Boyd, R. C., Frantz, E., \& Walsh, J. (2001). Emotional and behavioral impact of exposure to community violence in inner-city adolescents. Journal of Clinical Child Psychology, 30(2), 199-206. doi:10.1207/S15374424JCCP3002_7

Coulton, C., Pandey, S., \& Chow, J. (1990). Concentration of poverty and the changing ecology of low-income, urban neighborhoods: An analysis of the Cleveland area. Social Work Research \& Abstracts, 26(4), 5-16. doi:10.1093/swra/26.4.5

Cuellar, J., Jones, D. J., \& Sterrett, E. (2015). Examining parenting in the neighborhood context: A review. Journal of Child Family Studies, 24(1), 195-219. doi:10.1007/s10826-013-9826-y

Cummins, S., Macintyre, S., Davidson, S., \& Ellaway, A. (2005). Measuring neighbourhood social and material context: Generation and interpretation of ecological data from routine and non-routine sources. Health \& Place, 11(3), 249-260. doi:10.1016/j.healthplace.2004.05.003

Curley, A. M. (2010). Neighborhood institutions, facilities, and public space: A missing link for HOPE VI residents' development of social capital? Cityscape: A Journal of Policy Development and Research, 12(1), 33-63.

Dorsey, S., \& Forehand, R. (2003). The relation of social capital to child psychosocial adjustment difficulties: The role of positive parenting and neighborhood dangerousness. Journal of Psychopathology and Behavioral Assessment, 25, 11-23. doi:10.1023/A:1022295802449

Echeverria, S., Diez-Roux, A.V., \& Link, B. G. (2004). Reliability of self-reported neighborhood characteristics. Journal of Urban Health, 81(4), 682-700. doi:10.1093/jurban/jth151

Evans, G. W. (2006). Child development and the physical environment. Annual Review of Psychology, 57, 423-451. doi:10.1146/annurev.psych.57.102904.190057

Ferguson, K. T., Cassells, R. C., MacAllister, J. W, \& Evans, G. W. (2013). The physical environment and child development: An international review. International Journal of Psychology, 48(4), 437468. doi:10.1080/00207594.2013.804190 
International Journal of Child, Youth and Family Studies (2017) 8(3-4): 168-189

Fitzpatrick, K. M., Piko, B. F., Wright, D. R., \& LaGory, M. (2005). Depressive symptomatology, exposure to violence, and the role of social capital among African American adolescents. American Journal of Orthopsychiatry, 75, 262-274. doi:10.1037/0002-9432.75.2.262

Fredricks, J. A., Blumenfeld, P. C., \& Paris, A. (2004). School engagement: Potential of the concept, state of the evidence. Review of Educational Research, 74, 59-119. doi:10.3102/00346543074001059

Gonzales, N. A., Coxe, S., Roosa, M. W., White, R. M. B., Knight, G. P., Zeiders, K. H., \& Saenz, D. (2011). Economic hardship, neighborhood context, and parenting: Prospective effects on Mexican-American adolescents' mental health. American Journal of Community Psychology, 47, 98-113. doi:10.1007/s10464-010-9366-1

Gorman-Smith, D., \& Schoeny, M. (2009). Contextual influences on adolescent risk behavior: Community. Paper presented at the Institute of Medicine Committee on the Science of Adolescence Workshop, Washington, DC. Retrieved from http://www.nationalacademies.org/hmd/ /media/Files/Activity\%20Files/Children/AdolescenceW $\underline{\text { S/Commissioned\%20Papers/gorman-smith_paper.pdf }}$

Hadley-Ives, E., Stiffman, A. R., Elze, D., Johnson, S. D., \& Dore, P. (2000). Measuring neighborhood and school environments: Perceptual and aggregate approaches. Journal of Human Behavior in the Social Environment, 3(1), 1-28. doi:10.1300/J137v03n01_01

Henry, D., Gorman-Smith, D., Schoeny, M., \& Tolan, P. (2014). "Neighborhood matters": Assessment of neighborhood social processes. American Journal of Community Psychology, 54(3), 187-204. doi:10.1007/s10464-014-9681-z

Hu, L., \& Bentler, P. M. (1999). Cutoff criteria for fit indexes in covariance structure analysis: Conventional criteria versus new alternatives. Structural Equation Modeling, 6, 1-55. doi:10.1080/10705519909540118

Kline, R. B. (1998). Principles and practice of structural equations modeling. New York, NY: Guilford.

Kohen, D. E., Leventhal, T., Dahinten, V. S., \& McIntosh, C. N. (2008). Neighborhood disadvantage: Pathways of effects for young children. Child Development, 79(1), 156-69. doi:10.1111/j.1467$\underline{8624.2007 .01117 . x}$

Kotchick, B. A., Dorsey, S., \& Heller, L. (2005). Predictors of parenting among African American single mothers: Personal and contextual factors. Journal of Marriage and Family, 67, 448-460. doi:10.1111/j.0022-2445.2005.00127.x

Kubrin, C. E., \& Weitzer, R. (2003). New directions in social disorganization theory. Journal of Research in Crime and Delinquency, 40(4), 374-402. doi:10.1177/0022427803256238 
International Journal of Child, Youth and Family Studies (2017) 8(3-4): 168-189

Larsen, C. A. (2013). The rise and fall of social cohesion: The construction and de-construction of social trust in the USA, UK, Sweden and Denmark. Oxford, UK: Oxford University Press.

Law, J. H. J., \& Barber, B. K. (2007). Neighborhood conditions, parenting, and adolescent functioning. Journal of Human Behavior in the Social Environment, 14(4), 91-118. doi:10.1300/J137v14n04_05

Leventhal, T., \& Brooks-Gunn, J. (2000). The neighborhoods they live in: The effects of neighborhood residence on child and adolescent outcomes. Psychological Bulletin, 126, 309-337. doi:10.1037//0033-2909.126.2.309

Loehlin, J. C. (1998). Latent variable models: An introduction to factor, path, and structural analysis (3rd ed.). Mahwah, NJ: Lawrence Erlbaum Associates.

MacCallum, R. C., Browne, M. W., \& Sugawara, H. M. (1996). Power analysis and determination of sample size for covariance structure modeling. Psychological Methods, 1, 130-149. doi:10.1037/1082-989X.1.2.130

Marsh, H. W., Hau, K.-T., \& Wen, Z. (2004). In search of golden rules: Comment on hypothesistesting approaches to setting cutoff values for fit indexes and dangers in overgeneralizing $\mathrm{Hu}$ and Bentler's (1999) findings. Structual Equation Modeling, 11, 320-341. doi:10.1207/s15328007sem1103_2

Mast, B. D. (2010). Measuring neighborhood quality with survey data: A Bayesian approach. Cityscape: A Journal of Policy Development and Research, 12(3), 123-142.

McLoyd, V. C. (1990). The impact of economic hardship on Black families and children: Psychological distress, parenting, and socioemotional development. Child Development, 61, 311346. doi:10.2307/1131096

McNulty, T. L., \& Bellair, P. E. (2003). Explaining racial and ethnic differences in adolescent violence: Structural disadvantage, family well-being, and social capital. Justice Quarterly, 20(1), 1-31. doi:10.1080/07418820300095441

Molnar, B. E., Gortmaker, S. L., Bull, F. C., \& Buka, S. L. (2004) Unsafe to play? Neighborhood disorder and lack of safety predict reduced physical activity among urban children and adolescents. American Journal of Health Promotion, 18(5), 378-386. doi:10.4278/0890-1171$\underline{18.5 .378}$

Nasar, J. L., \& Fisher, B. (1993). "Hot spots" of fear of crime: A multiple-method investigation. Journal of Environmental Psychology, 13, 187-206. doi:10.1016/S0272-4944(05)80173-2

Nasar, J. L., Fisher, B., \& Grannis, M. (1993). Proximate physical cues to fear of crime. Landscape and Urban Planning, 26, 161-178. doi:10.1016/0169-2046(93)90014-5 
International Journal of Child, Youth and Family Studies (2017) 8(3-4): 168-189

Oppenheimer, L. (1988). The nature of social action: Social competence versus social comformism. In

B. H. Schneider, G. Attili, J. Nadel, \& R. P. Weissberg, (Eds.), Social competence in developmental perspective (pp. 41-70). Boston, MA: Kluwer Academic.

Raykov, T., \& Penev, S. (1999). On structural equation model equivalence. Multivariate Behavioral Research, 34(2), 199-244. doi:10.1207/S15327906Mb340204

Richters, J. E., \& Martinez, P. E. (1993). Violent communities, family choices, and children's chances: An algorithm for improving the odds. Development and Psychopathology, 5(4), 609-627. doi:10.1017/S0954579400006192

Rosenberg, S. A., Robinson, C. C., \& Beck, P. J. (1986). Measures of parent-infant interaction: An overview. Topics in Early Childhood Special Education, 6(2), 32-43. doi:10.1177/027112148600600204

Ross, C. E., \& Mirowsky, J. (2001). Neighborhood disadvantage, disorder, and health. Journal of Health \& Social Behavior, 42, 258-276.

Salzinger, S., Feldman, R. S., Stockhammer, T., \& Hood, J. (2002). An ecological framework for understanding risk for exposure to community violence and the effects of exposure on children and adolescents. Aggression and Violent Behavior, 7, 423-451. doi:10.1016/S1359$\underline{1789(01) 00078-7}$

Sampson, R. J., \& Groves, W. B. (1989). Community structure and crime: Testing social disorganization theory. American Journal of Sociology, 94, 774-802. doi:10.1086/229068

Sampson, R. J., Morenoff, J. D., \& Earls, F. (1999). Beyond social capital: Spatial dynamics of collective efficacy of children. American Sociological Review, 64, 633-660. doi:10.2307/2657367

Sampson, R. J., Raudenbush, S. W., \& Earls, F. (1997). Neighbourhoods and violent crime: A multilevel study of collective efficacy. Science, 227, 916-924. doi:10.1126/science.277.5328.918

Schechter, D. S., \& Willheim E. (2009). The effects of violent experience and maltreatment on infants and young children. In C. H Zeanah (Ed.), Handbook of infant mental health (3rd ed., pp. 197214). New York, NY: Guilford.

Shaw, C. R., \& McKay, H. D. (1942). Juvenile delinquency and urban areas: A study of rates of delinquents in relation to differential characteristics of local communities in American cities. Chicago, IL: University of Chicago Press.

Shonkoff, J. P., Boyce, W. T., \& McEwen, B. S. (2009). Neuroscience, molecular biology, and the childhood roots of health disparities: Building a new framework for health promotion and disease prevention. Journal of the American Medical Association 301(21), 2252-2259. doi:10.1001/jama.2009.754 
International Journal of Child, Youth and Family Studies (2017) 8(3-4): 168-189

Stark, R. (1987). Deviant places: A theory of the ecology of crime. Criminology, 25, 893-909. doi:10.1111/j.1745-9125.1987.tb00824.x

Sun, I. Y., Triplett, R. A., \& Gainey, R. R. (2004). Neighbourhood characteristics and crime: A test of Sampson and Groves' model of social disorganization. Western Criminology Review, 5(1), 1-16.

Taylor, R. B., Shumaker, S. A., \& Gottfredson, S. D. (1985). Neighborhood-level links between physical features and local sentiments: Deterioration, fear of crime, and confidence. Journal of Architectural Planning and Research, 2, 261-275.

Tolan, P. H., Gorman-Smith, D., \& Henry, D. B. (2003). The developmental ecology of urban males' youth violence. Developmental Psychology, 39(2), 274-291. doi:10.1037/0012-1649.39.2.274

Vieno, A., Nation, M., Perkins, D. D., Pastore, M., \& Santinello, M. (2010). Social capital, safety concerns, parenting, and early adolescents' antisocial behavior. Journal of Community Psychology, 38, 314-328. doi:10.1002/jcop.20366

White, R. M. B., Roosa, M. W., Weaver, S. R., \& Nair, R. L. (2009). Cultural and contextual influences on parenting in Mexican American families. Journal of Marriage and Family, 71, 6179. doi:10.1111/j.1741-3737.2008.00580.x

Wilson, W. J. (1996). When work disappears. New York, NY: Vintage Books. 